\title{
Prevalence of overweight and obesity in adolescent Tehrani students, 2000-2001: an epidemic health problem
}

\author{
B Mohammadpour-Ahranjani ${ }^{1, *}$, A Rashidi ${ }^{1}$, M Karandish $^{2}$, MR Eshraghian ${ }^{3}$ and \\ N Kalantari ${ }^{4}$ \\ 'Department of Nutrition Research, National Nutrition and Food Technology Research Institute, \\ Shaheed Beheshti University of Medical Sciences and Health Services, PO Box 19395-4741, Tehran, Iran: \\ ${ }^{2}$ Department of Nutrition, School of Paramedical Sciences, Ahwaz University of Medical Sciences and Health \\ Services, Ahwaz, Iran: ${ }^{3}$ Department of Epidemiology and Biostatistics, School of Public Health, \\ Tehran University of Medical Sciences and Health Services, Tehran, Iran: ${ }^{4}$ Department of Community Nutrition, \\ Faculty of Nutrition Sciences and Food Technology, Shaheed Beheshti University of Medical Sciences and Health \\ Services, Tehran, Iran
}

Submitted 28 April 2003: Accepted 1 December 2003

\begin{abstract}
Objective: Overweight has become a public health problem in most developing countries. Evidence suggests that adolescence is a critical period in determining adulthood obesity and its complications. The present study was carried out to assess the prevalence of overweight and obesity among secondary school students.

Design and setting: This descriptive study was conducted in Tehran city, 2000-2001. Body weight and height were measured and body mass index (BMI) values were calculated. Underweight, overweight and obesity were defined as $<5$ th, $\geq 85$ th and $\geq 95$ th percentile, respectively, of age- and sex-specific BMI values from the National Center for Health Statistics/Centers for Disease Control and Prevention (2000).

Subjects: Using a multistage sampling method, 2321 students (1068 males and 1253 females) aged 11-16 years were assessed in Tehran, the capital city of Iran.

Results: The overall prevalences of overweight and obesity were 21.1 and $7.8 \%$, respectively. The prevalence of overweight among girl students (i.e. 23.1\%; 95\% confidence interval (CI) 20.8-25.4) was significantly higher than that among boys (i.e. $18.8 \%$; 95\% CI 16.5-21.1, $P=0.01$ ) even after adjustment for age (odds ratio $1.26,95 \%$ CI $1.03-1.55, P=0.02$ ). No significant risk of obesity associated with age was found in girls or boys. In both sexes, median values of age-specific BMI in this study were statistically higher than corresponding values collected in Tehrani adolescents 10 years ago $(P=0.03)$. Similarly, a significant difference was seen between girl students in this study and the reference population $(P=0.03)$.

Conclusion: According to this study, overweight, especially in girls, should be considered an epidemic health problem among adolescent students in Tehran.
\end{abstract}

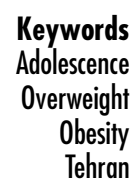

Overweight, as a main feature of epidemiological transition, has increased in most developing countries over the last two decades ${ }^{1}$. While the same phenomenon has recently been suggested in the Iranian population ${ }^{2}$, corresponding data on adolescents are limited. In the mean time, many observations have suggested that adolescence is a critical period in predicting the development of obesity as well as its short- and longterm complications later in life $\mathrm{e}^{3,4}$.

This cross-sectional study was carried out to assess the prevalences of overweight and obesity among secondary school students in Tehran city, 2000-2001.

\section{Subjects and methods}

In total, 2486 students (1147 males and 1339 females) aged 9-20 years were assessed in Tehran, the capital city of Iran, over four months (mid-October-midFebruary) during the 2000/01 school year. Using a multistage sampling method, 51 schools, as clusters, were selected systematically from all secondary schools in all of the 19 departments of education and training in Tehran city. In each cluster (school), 50 students were selected systematically from different educational grades. 
Body weight and height were measured to the nearest $0.1 \mathrm{~kg}$ and $0.5 \mathrm{~cm}$ using digital scales (Soehnle, Germany) and a non-stretch tape fixed to a flat vertical wall, respectively. Body mass index (BMI) values were calculated from the following equation: $\mathrm{BMI}=$ weight $(\mathrm{kg}) /$ height $(\mathrm{m})]^{2}$. Using reference growth charts from the National Center for Health Statistics (NCHS)/Centers for Disease Control and Prevention (CDC) $(2000)^{5}$, underweight, overweight and obesity were defined as $<5$ th, $\geq 85$ th and $\geq 95$ th percentile, respectively, of ageand sex-specific NHCS/CDC2000 BMI values ${ }^{6}$. We propose the 'underweight to obesity' ratio (UOR), as an indicator of the progress of epidemiological transition. The UOR tends to be around 1.0 in the reference population, to increase in undernourished populations and to decrease in over-nourished populations. The median (50th percentile) BMI values in students of different ages were compared with that of the reference population, as well as with corresponding values of 973 ( 473 boys and 500 girls) urban Tehrani adolescents aged 11-16 years ${ }^{7}$. The latter data were drawn from a national health survey in which a random cluster sample (one in every 1000 families) was studied in 1990-1992. Since educational coverage in the urban area of Tehran is more than $90 \%$, it is logical to compare this dataset, as baseline, with our study.

SPSS 10.0.5 software (SPSS Inc., Chicago, IL, USA) was used for statistical analysis. Differences in the prevalence rates of underweight, overweight and obesity between boys and girls were tested by chisquare statistics. Logistic regression was used to examine the association of age and sex with overweight and obesity. Differences in the set of age-specific median BMI values for each sex between different studies were analysed using the Wilcoxon matched-pairs signed-rank test. All values are presented as mean \pm standard deviation. All statistical inferences were made at $\alpha=0.05$.

The study protocol was approved by the Research Council at the National Nutrition and Food Technology Research Institute affiliated with Shaheed Beheshti University of Medical Sciences, Tehran and the Iranian Ministry of Education and Training.

\section{Results}

Weights and heights of 2321 adolescent students aged 1116 years (1068 boys, $13.7 \pm 1.54$ years; 1253 girls, $13.4 \pm 1.64$ years) were entered in the statistical analyses. BMI in boys and girls was $19.8 \pm 3.95$ and $20.6 \pm 4.11 \mathrm{~kg} \mathrm{~m}^{-2}$, respectively.

The overall prevalences of underweight, overweight and obesity were 5.7, 21.1 and 7.8\%, respectively. Ageand sex-specific prevalences of overweight and obesity are presented in Table 1 . The prevalence of overweight was significantly higher among girl students than among boys $(P=0.01)$. This difference remained significant after adjustment for age (odds ratio (OR) 1.26, 95\% confidence interval (CI) $1.03-1.55, P=0.02)$.

The observed difference between boys and girls was not significant for obesity even after adjustment for age (Table 1). No significant risk of obesity associated with age was found for girls and boys.

The UOR was 1.02 and 0.50 in boys and girls, respectively.

Logistic regression showed that the risk of overweight decreased with age (OR 0.93, 95\% CI 0.88-0.99, $P=0.03$ ); however, this was significant only among boys (OR 0.86 , 95\% CI $0.78-0.95, P=0.003$ ).

Median values of age-specific BMI in this study were statistically higher than corresponding values found among Tehrani adolescents 10 years ago $(P=0.03)^{7}$. Similarly, a significant difference was seen between girl students in this study and the reference population $(P=0.03)^{5}$. The difference in boys was insignificant (Figs 1 and 2).

\section{Discussion}

This study revealed the following:

- overweight was extensive among male and female adolescent students in Tehran city in 2000-2001;

- the prevalence of overweight was significantly higher among girls than among boys;

- the risk of overweight was higher in younger male adolescents;

Table 1 Prevalence (\%), and 95\% confidence interval (Cl), of overweight and obesity in adolescent Tehrani students, 2000-2001

\begin{tabular}{|c|c|c|c|c|c|c|}
\hline \multirow[b]{2}{*}{ Age (years) } & \multicolumn{3}{|c|}{ Males } & \multicolumn{3}{|c|}{ Females } \\
\hline & $n$ & Overweight $(95 \% \mathrm{Cl})$ & Obesity (95\% Cl) & $n$ & Overweight $(95 \% \mathrm{Cl})$ & Obesity (95\% Cl) \\
\hline 11 & 109 & $23.9(15.9-31.9)$ & $12.8(6.5-19.1)$ & 181 & $19.9(14.1-25.7)$ & $7.2(3.5-10.9)$ \\
\hline 12 & 171 & $21.6(15.4-27.8)$ & $7.0(3.2-10.8)$ & 270 & $27.8(22.5-33.1)$ & $10.0(6.4-13.6)$ \\
\hline 13 & 204 & $25.0(19.1-30.9)$ & $7.8(4.1-11.5)$ & 231 & $19.9(14.8-25.0)$ & $6.9(3.6-10.2)$ \\
\hline 14 & 220 & $15.5(10.7-20.3)$ & $5.5(2.5-8.5)$ & 219 & $25.6(19.8-31.4)$ & $8.7(5.0-12.4)$ \\
\hline 15 & 220 & $13.6(9.1-18.1)$ & $6.4(3.2-9.6)$ & 169 & $21.9(15.7-28.1)$ & $7.7(3.7-11.7)$ \\
\hline 16 & 144 & $16.0(10.0-22.0)$ & $6.9(2.8-11.0)$ & 183 & $21.3(15.4-27.2)$ & $8.7(4.7-12.7)$ \\
\hline Total & 1068 & $18.8(16.5-21.1)$ & $7.3(5.8-8.8)$ & 1253 & $23.1(20.8-25.4)$ & $8.3(6.8-9.8)$ \\
\hline
\end{tabular}




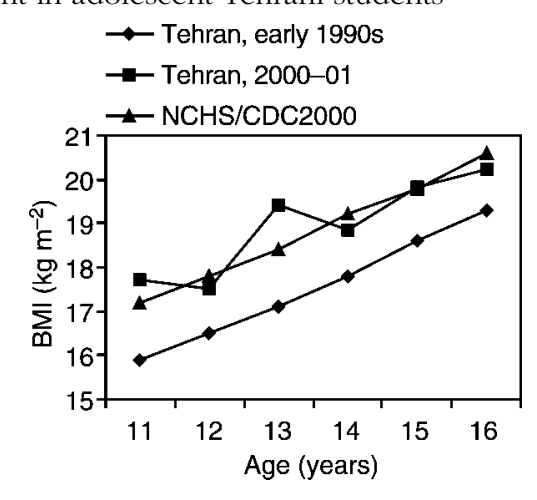

Fig. 1 Median (50th percentile) BMI for boys in this study (Tehran, 2000-01), Tehrani boys 10 years ago (Tehran, early 1990s) and the reference population (NCHS/CDC2000). BMI - body mass index; NCHS - National Center for Health Statistics; CDC - Centers for Disease Control and Prevention

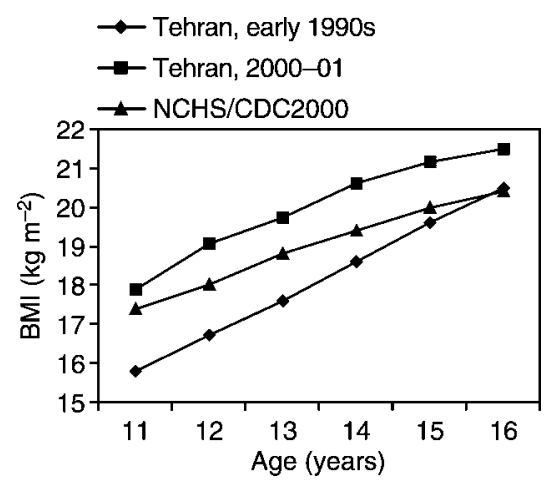

Fig. 2 Median (50th percentile) BMl for girls in this study (Tehran, 2000-01), Tehrani girls 10 years ago (Tehran, early 1990s) and the reference population (NCHS/CDC2000). BMI - body mass index; NCHS - National Center for Health Statistics; CDC - Centers for Disease Control and Prevention

- the prevalence of adolescent overweight in Tehran seems to have increased from 1991 to 2001; and

- compared with reference growth charts, our female adolescents had significantly higher age-adjusted BMI values.

Overweight and obesity, as a feature of epidemiological transition, have long been recognised as a public health problem in industrialised countries ${ }^{6,8-10}$. Recent evidence suggests that a similar phenomenon is emerging with the same velocity in most developing countries ${ }^{6,11,12}$. The prevalences of overweight and obesity found in the present study are consistent with findings from other developing countries in the region ${ }^{11,12}$. In addition, the higher prevalence of overweight and obesity among female adolescents is similar to what has been seen in some countries $8,11,13$, as well as in the previous study in a similar population ${ }^{7}$. However, this has not been a consistent finding ${ }^{14,15}$. In our study, the prevalence of overweight was significantly higher in girls. While we could not find a statistically significant difference in obesity prevalence between boys and girls, obesity tended to be more frequent among the latter, which might be attributable to the level and duration of physical activity. No suggestion can be made at present to justify the higher prevalence of overweight in younger boys.

It seems that increasing fat intake is one of the most important aspects of nutrition transition in $\operatorname{Iran}^{16}$, which can somehow explain the changes that have occurred in the prevalence of overweight over the last 10 years. To our knowledge, no study has been published yet to show changes in physical activity as another important feature of lifestyle in Iran.

As shown in Figs 1 and 2, Tehrani girl students, not boys, had higher median BMIs than their reference-age counterparts. The same was found when we compared our data with a previously proposed reference, i.e. World Health Organization standards (not shown) ${ }^{17}$. Frequency, intensity and duration of physical activity seem to be the main determinants of better fitness in male Tehrani students compared with females.

Finally, the low ratio of underweight to obesity in girl students can be considered as further evidence of the progress of the epidemiological transition in Iran, especially when compared with the corresponding value in adolescent boys.

\section{Acknowledgements}

We would like to express our gratitude to our enumerators, A Abou-Nabi, M Hozouri, MR Khosh-fetrat, A Movahedi, A Najjarzadeh, A Paykar, R Parastesh, A Saedi and L Zellipour, for their technical support. We are also grateful to B Tayyebi for her assistance in editing the manuscript. The study was supported financially (grant nos. 18/5496 and 18/5729) by the National Nutrition and Food Technology Research Institute.

\section{References}

1 Popkin BM. The nutrition transition and obesity in the developing world. Journal of Nutrition 2001; 131: 871S-3S.

2 Ghassemi H, Harrison G, Mohammad K. An accelerated nutrition transition in Iran. Public Health Nutrition 2002; 5(1A): $149-55$.

3 Dietz WH. Critical periods in childhood for the development of obesity. American Journal of Clinical Nutrition 1994; 59: 955-9.

4 Must A, Strauss RS. Risks and consequences of childhood and adolescent obesity. International Journal of Obesity and Related Metabolic Disorders 1999; 23(Suppl 2): S2-11.

5 National Center for Health Statistics in collaboration with the National Center for Chronic Disease Prevention and Health Promotion. Body mass index-for-age percentiles, 2000 [online]. Available at www.cdc.gov/growthcharts

6 World Health Organization (WHO). Obesity, Preventing and Managing the Global Epidemic. Report of a WHO Consultation on Obesity, Geneva, 3-5 June 1997. Geneva: WHO, 1998.

7 Hosseini M, Carpenter RG, Mohammad K, Jones ME. Standardized percentile curves of body mass index of Iranian children compared to the US population reference. 
International Journal of Obesity and Related Metabolic Disorders 1999; 23: 783-6.

8 Hanley AJ, Harris SB, Gittelsohn J, Wolever TM, Saksvig B, Zinman B. Overweight among children and adolescents in a Native Canadian community: prevalence and associated factors. American Journal of Clinical Nutrition 2000; 71 : 693-700.

9 Troiano RP, Flegal KM, Kuczmarski RJ, Campbell SM, Johnson CL. Overweight prevalence and trends for children and adolescents. The National Health and Nutrition Examination Survey, 1963 to 1991. Archives of Pediatrics \& Adolescent Medicine 1995; 149: 1085-91.

10 Thakur N, D'Amico F. Relationship of nutrition knowledge and obesity in adolescence. Family Medicine 1999; 31: $122-7$.

11 Amine EK. The prevalence of obesity among male and female preschool children and school students in Qatar (a national study). In: Proceedings of the 9th World Congress on Clinical Nutrition, London, 24-26 June 2002. UK: University of Westminster, 2002; 146.

12 Iyer UM, Parikh A, Gandhi H, Mani UV. Childhood obesity: prevalence and risk factor analysis. In: Proceedings of the 9 th World Congress on Clinical Nutrition, London, 24-26 June 2002. UK: University of Westminster, 2002; 181.

13 Rios M, Fluiters E, Perez-Mendez LF, Garcia-Mayor EG, Gracia-Mayor RV. Prevalence of childhood overweight in Northwestern Spain: a comparative study of two periods with a ten year interval. International Journal of Obesity and Related Metabolic Disorders 1999; 23: 1095-8.

14 Leung SS, Ng MY, Lau TF. Prevalence of obesity in Hong Kong children and adolescents aged 3-18 year [abstract]. Chung Hua Yu Fang I Hsueh Tsa Chih 1995; 29: 270-2.

15 Moon HN, Hong SJ, Suh SJ. The prevalence of obesity in children and adolescents [abstract]. Korean Journal of Nutrition 1992; 25: 413-8.

16 Ghassemi H. Food and nutrition security in Iran: studies of planning and implementation models. Final report of research project, National Nutrition and Food Technology Research Institute, Tehran, 1998 [in Farsi].

17 World Health Organization (WHO). Physical Status: The Use and Interpretation of Anthropometry. WHO Technical Report Series No. 854. Geneva: WHO, 1995. 